\title{
Lack of transgenerational effects of ionizing radiation exposure from the Chernobyl accident
}

\author{
Meredith Yeager ${ }^{1,2 *}+$, Mitchell J. Machiela ${ }^{1} \uparrow$, Prachi Kothiyal ${ }^{1,3}$, Michael Dean ${ }^{1,2}$, Clara Bodelon ${ }^{1}$, Shalabh \\ Suman $^{1,2}$, Mingyi Wang ${ }^{1,2}$, Lisa Mirabello ${ }^{1}$, Chase W. Nelson ${ }^{4,5}$, Weiyin Zhou ${ }^{1,2}$, Cameron Palmer, ${ }^{1,2}$, Bari \\ Ballew $^{1,2}$, Leandro M. Colli ${ }^{1,6}$, Neal D. Freedman', Casey Dagnall ${ }^{1,2}$, Amy Hutchinson ${ }^{1,2}$, Vibha Vij ${ }^{1}$, Yosi \\ Maruvka $^{7,11}$, Maureen Hatch ${ }^{1}$, Iryna Illienko ${ }^{8}$, Yuri Belayev ${ }^{8}$, Nori Nakamura ${ }^{9}$, Vadim Chumak $^{8}$, Elena \\ Bakhanova $^{8}$, David Belyi ${ }^{8}$, Victor Kryuchkov ${ }^{10}$, Ivan Golovanov ${ }^{10}$, Natalia Gudzenko ${ }^{8}$, Elizabeth K. Cahoon', \\ Paul Albert', Vladimir Drozdovitch', Mark P. Little' ${ }^{1}$, Kiyohiko Mabuchi', ${ }^{1}$ Chip Stewart ${ }^{7}$, Gad Getz ${ }^{7,11,12,13}$, \\ Dimitry Bazyka ${ }^{8}$, Amy Berrington de Gonzalez ${ }^{1}$, Stephen J. Chanock ${ }^{1 *}$
}

\begin{abstract}
1Division of Cancer Epidemiology and Genetics, National Cancer Institute, Rockville, MD 20892, USA. ${ }^{2}$ Cancer Genomics Research Laboratory, Frederick National Laboratory for Cancer Research, Frederick, MD 21701, USA. ${ }^{3}$ SymbioSeq LLC, Arlington, VA 20148, USA. Biodiversity Research Center, Academia Sinica, Taipei, 11529, Taiwan. 5 Institute for Comparative Genomics, American Museum of Natural History, New York, NY 10024, USA. 6 Department of Medical Imaging, Hematology, and Oncology, Ribeirao Preto Medical School, University of Sao Paulo, Ribeirao Preto; SP, 14049-900, Brazil. ${ }^{7 B}$ Broad Institute of Harvard and Massachusetts Institute of Technology, Cambridge, MA 02142, USA. ${ }^{N}$ National Research Centre for Radiation Medicine, 53 Yu. Illienka Street, Kyiv, 04050, Ukraine. ${ }^{9}$ Department of Molecular Biosciences, Radiation Effects Research Foundation, 5-2 Hijiyama Park, Minami-ku, Hiroshima, 732-0815, Japan. ${ }^{10}$ Burnasyan Federal Medical and Biophysical Centre, 46 Zhivopisnaya Street, Moscow, 123182, Russia. ${ }^{11}$ Center for Cancer Research, Massachusetts General Hospital, Boston, MA 02114, USA. ${ }^{12}$ Department of Pathology, Massachusetts General Hospital, Boston, MA 02114, USA. ${ }^{13}$ Harvard Medical School, Boston, MA 02115, USA.
\end{abstract}

*Corresponding author: chanocks@mail.nih.gov (S.J.C.); yeagerm@mail.nih.gov (M.Y.)

†These authors contributed equally to this work.

Effects of radiation exposure from the Chernobyl nuclear accident remain a topic of interest. We investigated whether children born to parents employed as cleanup workers or exposed to occupational and environmental ionizing radiation post-accident were born with more germline de novo mutations (DNMs). Whole-genome sequencing of 130 children (born 1987-2002) and their parents did not reveal an increase in the rates, distributions, or types of DNMs versus previous studies. We find no elevation in total DNMs regardless of cumulative preconception gonadal paternal (mean $=365 \mathrm{mGy}$, range $=0-4,080 \mathrm{mGy}$ ) or maternal (mean $=19 \mathrm{mGy}$, range $=0-550 \mathrm{mGy}$ ) exposure to ionizing radiation and conclude over this exposure range, evidence is lacking for a substantial effect on germline DNMs in humans, suggesting minimal impact on health of subsequent generations.

Nearly all inherited genetic variation is present in the germline DNA of at least one parent; however, a small number of transmitted variants are unique, having arisen due to random mutations in gametes (sperm and oocytes), and are known as de novo mutations (DNMs). DNMs are critical building blocks of evolution and the only class of genomic variation that has not undergone extensive evolutionary purifying selection (purging of highly deleterious but non-lethal variants), making DNMs a unique form of inherited variation different from the genetic variation investigated in mapping complex traits and diseases (1). DNMs have been of intense interest because of their role in human disease, particularly neurodevelopmental disorders $(2,3)$.

Only recently has it been feasible to comprehensively investigate DNMs genome-wide at the population level in humans by whole-genome sequencing (WGS) of mother/ father/child trios. Recent reports of human DNMs characterized by WGS of trios estimate between 50 and 100 new mutations arise per individual per generation $(2,4-8)$, consistent with the population genetic estimate that the human mutation rate for single-nucleotide variants (SNVs) is approximately $1 \times 10^{-8}$ per site per generation $(9,10)$. The strongest predictor of DNMs per individual is paternal age at conception $(2-6,8)$ with an increase of $0.64-1.51$ per one-year increase in paternal age $(6,8,11)$ while a maternal effect of approximately 0.35 per one-year increase in age was observed $(6,8,12)$. Transgenerational studies of radiation exposure have primarily focused on disease (cancer, reproductive, and developmental) outcomes and have reported inconclusive results $(13,14)$.

Exposure to ionizing radiation is known to increase DNA mutagenesis above background rates $(15,16)$. Animal and cellular studies suggest high doses of ionizing radiation can lead to DNMs in offspring, particularly through double-stranded breaks $(13,17)$. Human studies have sought a biomarker of prior radiation injury $(13,18,19)$, but have examined a small number of minisatellites and microsatellites, yielding inconclusive results $(20-23)$. A WGS study of three trios from 
survivors of the atomic bomb in Nagasaki did not reveal a high load of DNMs (20), while a single-nucleotide polymorphism (SNP) array study of 12 families exposed to low doses of Caesium-137 from the Goiania accident in Brazil reported an increase in large de novo copy-number variants (24). No large comprehensive effort has explored DNMs genome-wide in children born from parents exposed to moderately high amounts of ionizing radiation yet possible genetic effects have remained a concern for radiation-exposed populations, such as the Fukushima evacuees (25).

Herein, we examine whether rates of germline DNMs were elevated in children born to parents exposed to ionizing radiation from the 1986 Chernobyl (Chornobyl in Ukrainian) disaster, where levels of exposure have been rigorously reconstructed and well-documented (26). Our study focused on children born of enlisted cleanup workers ("liquidators") and evacuees from the town of Pripyat or other settlements within the $70-\mathrm{km}$ zone around Chernobyl Nuclear Power Plant in Ukraine (27) after the meltdown, some of whom had extremely high levels of radiation exposure and several of whom experienced acute radiation syndrome. We performed Illumina paired-end WGS (average coverage 80X), SNP microarray analysis, and relative telomere length assessment on available samples from 130 children from 105 mother-father pairs. The parents had varying combinations of elevated gonadal ionizing radiation exposure from the accident (tables $\mathrm{S} 1$ to S3), and included a combination of exposed fathers, exposed mothers, both parents exposed and neither parent exposed (27). Fathers' cumulative gonadal ionizing radiation dose ("dose") at conception ranged from 0 to $4,080 \mathrm{mGy}$ $($ mean $=365$, median $=29$, standard deviation $(\mathrm{sd})=685)$ with 17 exposed to $>1000$ mGy, whereas mothers' dose ranged from 0 to 550 mGy (mean $=19$, median $=2.1$, $\mathrm{sd}=72)$ with only 2 exposed to $>500$ mGy (table S3). Paternal age at exposure ranged from 12-41 years, and maternal from 10-33 years. Paternal mean age at conception was 29 (range $=18-52, \mathrm{sd}=$ 5.7) while maternal mean age was 27 (range $=18-39$, $\mathrm{sd}=5.2$ ). 58 (45\%) children were female and 72 (55\%) were male. Children born 46 or more weeks after the Chernobyl accident were included; birth years were between 1987 and 2002 (52\% prior to 1992). There were 23 families with two or three siblings analyzed, but no twins. Principal component analysis (PCA) revealed nearly all parents shared common Eastern European heritage (fig. S1), and pairwise identity-by-descent analysis revealed four first-degree relative sets among the parents.

Two modified MIE filtering strategies were applied for post-variant calling and detection of Mendelian inconsistency error (MIE) determination (8, 28). All putative DNMs passing filtering criteria were examined manually, and the total number of DNMs were tallied for each the following classes, reflecting distinct mutational mechanisms: a) single- nucleotide variants (SNVs), b) small insertions/deletions (indels), c) complex variants (variants that arose from a complicated mutational event), and d) SNV/indel clusters, which are two or more variants that occur closer than expected by chance (as defined by Jónsson et al. (6)) (Table 1). Each instance of a complex variant or SNV/indel cluster was counted once, effectively assuming that clustered changes occurred together during one replication cycle. Length variants at microsatellite loci were examined separately since they have been previously reported as a potentially important class of mutation following radiation exposure (21, 22, 29-31). While DNMs involving microsatellite loci were analyzed separately, they were tallied overall with indels. All variants are provided in table $\mathrm{S} 1$.

There was no evidence for a relationship between the total number of DNMs and preconception ionizing radiation dose (cumulative estimated gonadal dose at 38 weeks before birth) for maternal (-0.02 DNM per mGy, 95\% CI: -0.04-0.007, p = $0.17)$ or paternal $(-0.0007 \mathrm{DNM}$ per mGy, 95\% CI: $-0.003-$ $0.002, \mathrm{p}=0.56$ ) exposures (Table 2 and fig. S2). In an analysis restricted to DNMs with known parent-of-origin (42\%; Table 1), no effect of radiation was observed (table S4) whereas the effect of parental age remained robust; the parent-of-origin point estimates for paternal and maternal age effects were 0.71 and 0.28 , respectively. Further investigation did not reveal evidence for an effect of preconception dose for any individual class of DNMs evaluated (table S5). Sensitivity analysis conducted with doses truncated at $1000 \mathrm{mGy}$ or log transformed $(\ln (1+\operatorname{dose}(m G y)))$ did not reveal an impact of maternal and paternal dose modeling on association with DNMs (Table 3). We further investigated categorical dose levels and found no increase in DNMs for any dose category, even $1000+$ mGy paternal dose (table S6). No effect of time since exposure was observed between parental preconception ionizing radiation exposure and DNM count for children born in the years immediately following the Chernobyl accident (Fig. 1). Moreover, when restricting to SNVs, there was no difference in the distribution of nucleotide substitutions based on quartile of maternal and paternal dose (fig. S3). Furthermore, the rates and types (molecular spectra) of DNMs observed in the current study were similar to those observed in prior studies conducted in general populations (Fig. 2 and fig. S4) $(2-4,6,8)$.

Since lifestyle exposures such as smoking have been associated with alterations of DNA (for example, mosaic loss of Y chromosome (32)), we also investigated possible effects of prenatal parental alcohol consumption and smoking on DNMs. We observed no association between the number of DNMs and either paternal tobacco smoking at conception (6.78, 95\% CI $=-16.62-14.87, \mathrm{p}=0.13$, Table 2 and Fig. 1 ) or maternal tobacco smoking at conception $(23.38,95 \% \mathrm{CI}=$ $-2.00-48.77, \mathrm{p}=0.07$, Table 2 and Fig. 1). Similarly, no effect 
was observed for increasing levels of paternal $(p=0.12)$ or maternal ( $\mathrm{p}=0.12)$ preconception alcohol consumption. In addition, sequencing batch had no impact on the number of DNMs (4.45, 95\% CI = -5.07-13.97, $\mathrm{p}=0.34)$.

Relative telomere length was measured by qPCR (33) in participants to investigate the potential transgenerational impact of parental ionizing radiation on leukocyte telomere length in children. As expected, an overall relationship was observed between increasing age at blood draw and shorter relative telomere length due to age-related telomere length attrition ( $\mathrm{p}=4.49 \times 10^{-19}$, fig. S5). We did not observe an effect of paternal or maternal age at conception on relative telomere length in adult children ( $\mathrm{p}=0.95$ and 0.06 , respectively; table S7). While our analysis did not find evidence for an effect of total paternal preconception ionizing radiation exposure on relative leukocyte telomere length $(\mathrm{p}=0.88)$, we did observe a possible effect of total maternal preconception exposure that requires confirmation $\left(-2.75 \times 10^{-4}, 95 \% \mathrm{CI}=\right.$ $-5.20 \times 10^{-4}--2.90 \times 10^{-5}, \mathrm{p}=0.03$; table S7). There was no evidence for a transgenerational effect of paternal or maternal smoking on child's telomere length $(\mathrm{p}=0.91$ and 0.22 , respectively, table S7).

Although it is reassuring that no transgenerational effects of ionizing radiation were observed in adult children of Chernobyl cleanup workers and evacuees in the current study, additional investigation is needed to address the effects of acute high-dose parental gonadal exposure closer to conception. The upper 95\% confidence bound suggests the largest effect consistent with our data is $<1$ DNM per $100 \mathrm{mGy}$ from paternal or maternal exposure (Table 3 and tables S8 and S9). Previously, Dubrova et al. $(22,29)$ reported a two-fold increase in mini-satellite mutations in children born to parents living in a highly exposed region of Belarus. Weinberg et al. (34) reported an increase in the mutation rate at microsatellite loci among children born to cleanup workers. Subsequent small studies have not reported an increased mini-satellite or microsatellite mutation rate in children of cleanup workers, including those with low doses (0.09-0.23 Gy) $(21,30,35)$ or in children of the atomic-bomb survivors of Hiroshima or Nagasaki (31).

Our study evaluated peripheral blood from adult children conceived months or years after the Chernobyl accident, which limited the ability to assess exposure closer to conception; however, there was no evidence of notable differences in DNMs in children born the following year (1987). Since these families were recruited several decades after the accident, we acknowledge potential survivor bias among sampled children, although this is unlikely since there is no consistent demonstration in humans of sustained clinical effects of preconception ionizing radiation exposure (36). The number of parental gonadal radiation-induced double strand breaks could be fewer than anticipated based on animal data, which often assesses acute exposure (as a single burst) at higher doses $(2-4 \mathrm{~Gy} ;(13,37))$. Doses to the Chernobyl liquidators were mostly lower and exposure was fractionated over an extended period of time, which could have decreased the probability of gonadal DNM events. Moreover, it is plausible that the balance between radiation-induced mutations and accurate repair over time favored the latter. Additionally, there could have been a loss of power due to dose errors. Further human studies are needed to investigate the frequency of radiation-induced mutations and the subsequent response to address both the accuracy and efficiency of DNA repair. In a genomic landscape analysis of 440 cases of papillary thyroid cancer following the Chernobyl accident, increased radiation exposure was associated with a shift in tumor drivers from point mutations to small indels and non-homologous end joining events underlying fusions and other structural variants (38). Notably, there was no evidence of a radiationspecific single base substitution signature, gene expression pattern or methylation profile in cases of thyroid cancer with comparable radiation exposure history; instead, these were strongly associated with the tumor driver.

The rate, class distribution, and SNV type distribution of DNMs in adult children born to parents exposed to ionizing radiation, specifically of the type and amount relevant to Chernobyl cleanup workers and evacuees, are comparable to those reported in the general population. No effect of radiation on the specific classes of DNMs (SNVs, indels, complex variants, or clusters) was observed (table S5). Paternal age remains the strongest contributor to DNMs, although with maternal age DNMs also increase albeit with lower magnitude (Table 2 and table S4; (12)). Our study sample did not include mothers with high exposure ( $>1 \mathrm{~Gy}$ ), but lower maternal dose was not associated with elevated DNMs, consistent with animal studies (13). Furthermore, our analysis of 130 adult children from 105 couples using 80X coverage of short-read technology suggests that if such effects on human germline DNA occur, they are uncommon or of small magnitude. This is one of the first studies to systematically evaluate alterations in human mutation rates in response to a man-made disaster, such as accidental radiation exposure. Investigation of trios drawn from survivors of the Hiroshima atomic bomb could shed further light on this public health question. In conclusion, children of individuals exposed to either occupational or environmental radiation do not appear to experience elevated rates of DNMs from their parents' exposure. Thus, our study does not provide support for a transgenerational effect of ionizing radiation on germline DNA in humans.

\section{REFERENCES AND NOTES}

1. V. Tam, N. Patel, M. Turcotte, Y. Bossé, G. Paré, D. Meyre, Benefits and limitations of genome-wide association studies. Nat. Rev. Genet. 20, 467-484 (2019). doi:10.1038/s41576-019-0127-1 Medline

2. A. Kong, M. L. Frigge, G. Masson, S. Besenbacher, P. Sulem, G. Magnusson, S. A. 
Gudjonsson, A. Sigurdsson, A. Jonasdottir, A. Jonasdottir, W. S. W. Wong, G. Sigurdsson, G. B. Walters, S. Steinberg, H. Helgason, G. Thorleifsson, D. F. Gudbjartsson, A. Helgason, O. T. Magnusson, U. Thorsteinsdottir, K. Stefansson, Rate of de novo mutations and the importance of father's age to disease risk. Nature 488, 471-475 (2012). doi:10.1038/nature11396 Medline

3. J. J. Michaelson, Y. Shi, M. Gujral, H. Zheng, D. Malhotra, X. Jin, M. Jian, G. Liu, D. Greer, A. Bhandari, W. Wu, R. Corominas, A. Peoples, A. Koren, A. Gore, S. Kang, G. N. Lin, J. Estabillo, T. Gadomski, B. Singh, K. Zhang, N. Akshoomoff, C. Corsello, S. McCarroll, L. M. lakoucheva, Y. Li, J. Wang, J. Sebat, Whole-genome sequencing in autism identifies hot spots for de novo germline mutation. Cell 151, 1431-1442 (2012). doi:10.1016/i.cell.2012.11.019 Medline

4. L. C. Francioli, P. P. Polak, A. Koren, A. Menelaou, S. Chun, I. Renkens, C. M. van Duijn, M. Swertz, C. Wijmenga, G. van Ommen, P. E. Slagboom, D. I. Boomsma, K. Ye, V. Guryev, P. F. Arndt, W. P. Kloosterman, P. I. W. de Bakker, S. R. Sunyaev; Genome of the Netherlands Consortium, Genome-wide patterns and properties of de novo mutations in humans. Nat. Genet. 47, 822-826 (2015). doi:10.1038/ng.3292 Medline

5. J. M. Goldmann, V. B. Seplyarskiy, W. S. W. Wong, T. Vilboux, P. B. Neerincx, D. L. Bodian, B. D. Solomon, J. A. Veltman, J. F. Deeken, C. Gilissen, J. E. Niederhuber, Germline de novo mutation clusters arise during oocyte aging in genomic regions with high double-strand-break incidence. Nat. Genet. 50, 487-492 (2018). doi:10.1038/s41588-018-0071-6 Medline

6. H. Jónsson, P. Sulem, B. Kehr, S. Kristmundsdottir, F. Zink, E. Hjartarson, M. T. Hardarson, K. E. Hjorleifsson, H. P. Eggertsson, S. A. Gudjonsson, L. D. Ward, G. A. Arnadottir, E. A. Helgason, H. Helgason, A. Gylfason, A. Jonasdottir, A. Jonasdottir, T. Rafnar, M. Frigge, S. N. Stacey, O. Th Magnusson, U. Thorsteinsdottir, G. Masson, A. Kong, B. V. Halldorsson, A. Helgason, D. F. Gudbjartsson, K. Stefansson, Parental influence on human germline de novo mutations in 1,548 trios from Iceland. Nature 549, 519-522 (2017). doi:10.1038/nature24018 Medline

7. R. Rahbari, A. Wuster, S. J. Lindsay, R. J. Hardwick, L. B. Alexandrov, S. A. Turki, A. Dominiczak, A. Morris, D. Porteous, B. Smith, M. R. Stratton, M. E. Hurles; UK10K Consortium, Timing, rates and spectra of human germline mutation. Nat. Genet. 48, 126-133 (2016). doi:10.1038/ng.3469 Medline

8. W. S. Wong, B. D. Solomon, D. L. Bodian, P. Kothiyal, G. Eley, K. C. Huddleston, R. Baker, D. C. Thach, R. K. Iyer, J. G. Vockley, J. E. Niederhuber, New observations on maternal age effect on germline de novo mutations. Nat. Commun. 7, 10486 (2016). doi:10.1038/ncomms10486 Medline

9. J. W. Drake, B. Charlesworth, D. Charlesworth, J. F. Crow, Rates of spontaneous mutation. Genetics 148, 1667-1686 (1998). doi:10.1093/genetics/148.4.1667 Medline

10. M. W. Nachman, S. L. Crowell, Estimate of the mutation rate per nucleotide in humans. Genetics 156, 297-304 (2000). Medline

11. J. F. Crow, The origins, patterns and implications of human spontaneous mutation. Nat. Rev. Genet. 1, 40-47 (2000). doi:10.1038/35049558 Medline

12. Z. Gao, P. Moorjani, T. A. Sasani, B. S. Pedersen, A. R. Quinlan, L. B. Jorde, G. Amster, M. Przeworski, Overlooked roles of DNA damage and maternal age in generating human germline mutations. Proc. Natl. Acad. Sci. U.S.A. 116, 94919500 (2019). doi:10.1073/pnas.1901259116 Medline

13. M. P. Little, D. T. Goodhead, B. A. Bridges, S. D. Bouffler, Evidence relevant to untargeted and transgenerational effects in the offspring of irradiated parents. Mutat. Res. 753, 50-67 (2013). doi:10.1016/i.mrrev.2013.04.001 Medline

14. N. R. Council, in (US) Committee on Health Effects of Exposure to Low Levels of lonizing Radiations (BEIR VII). (Washington (DC), 2006).

15. H. J. Muller, The production of mutations by x-rays. Proc. Natl. Acad. Sci. U.S.A. 14 , 714-726 (1928). doi:10.1073/pnas.14.9.714 Medline

16. Learning the lessons of Chernobyl: Time is running out. Lancet 395, 1012 (2020). doi:10.1016/S0140-6736(20)30687-5 Medline

17. W. L. Russell, Mutation frequencies in female mice and the estimation of genetic hazards of radiation in women. Proc. Natl. Acad. Sci. U.S.A. 74, 3523-3527 (1977). doi:10.1073/pnas.74.8.3523 Medline

18. A. Fucic, G. Brunborg, R. Lasan, D. Jezek, L. E. Knudsen, D. F. Merlo, Genomic damage in children accidentally exposed to ionizing radiation: A review of the literature. Mutat. Res. 658, 111-123 (2008). doi:10.1016/j.mrrev.2007.11.003 Medline
19. N. Nakamura, A. Suyama, A. Noda, Y. Kodama, Radiation effects on human heredity. Annu. Rev. Genet. 47, 33-50 (2013). doi:10.1146/annurev-genet-111212133501 Medline

20. M. Horai, H. Mishima, C. Hayashida, A. Kinoshita, Y. Nakane, T. Matsuo, K. Tsuruda, K. Yanagihara, S. Sato, D. Imanishi, Y. Imaizumi, T. Hata, Y. Miyazaki, K. I. Yoshiura, Detection of de novo single nucleotide variants in offspring of atomicbomb survivors close to the hypocenter by whole-genome sequencing. J. Hum. Genet. 63, 357-363 (2018). doi:10.1038/s10038-017-0392-9 Medline

21. R. J. Slebos, R. E. Little, D. M. Umbach, Y. Antipkin, T. D. Zadaorozhnaja, N. A. Mendel, C. A. Sommer, K. Conway, E. Parrish, S. Gulino, J. A. Taylor, Mini- and microsatellite mutations in children from Chernobyl accident cleanup workers. Mutat. Res. 559, 143-151 (2004). doi:10.1016/i.mrgentox.2004.01.003 Medline

22. Y. E. Dubrova, V. N. Nesterov, N. G. Krouchinsky, V. A. Ostapenko, R. Neumann, D. L. Neil, A. J. Jeffreys, Human minisatellite mutation rate after the Chernobyl accident. Nature 380, 683-686 (1996). doi:10.1038/380683a0 Medline

23. C. Turner, C. Killoran, N. S. T. Thomas, M. Rosenberg, N. A. Chuzhanova, J. Johnston, Y. Kemel, D. N. Cooper, L. G. Biesecker, Human genetic disease caused by de novo mitochondrial-nuclear DNA transfer. Hum. Genet. 112, 303-309 (2003). doi:10.1007/s00439-002-0892-2 Medline

24. E. O. A. Costa, I. P. Pinto, M. W. Gonçalves, J. F. da Silva, L. G. Oliveira, A. S. da Cruz, D. M. E. Silva, C. C. da Silva, R. W. Pereira, A. D. da Cruz, Small de novo CNVs as biomarkers of parental exposure to low doses of ionizing radiation of caesium137. Sci. Rep. 8, 5914 (2018). doi:10.1038/s41598-018-23813-5 Medline

25. K. Kamiya, K. Ozasa, S. Akiba, O. Niwa, K. Kodama, N. Takamura, E. K. Zaharieva, Y. Kimura, R. Wakeford, Long-term effects of radiation exposure on health. Lancet 386, 469-478 (2015). doi:10.1016/S0140-6736(15)61167-9 Medline

26. V. Chumak, E. Bakhanova, V. Kryuchkov, I. Golovanov, K. Chizhov, D. Bazyka, N. Gudzenko, N. Trotsuk, K. Mabuchi, M. Hatch, E. K. Cahoon, M. P. Little, T. Kukhta, A. Berrington de Gonzalez, S. J. Chanock, V. Drozdovitch, Estimation of radiation gonadal doses for the American-Ukrainian trio study of parental irradiation in Chornobyl cleanup workers and evacuees and germline mutations in their offspring. J. Radiol. Prot. 10.1088/1361-6498/abfOf4 (2021). doi:10.1088/13616498/abfOf4 Medline

27. D. Bazyka, M. Hatch, N. Gudzenko, E. K. Cahoon, V. Drozdovitch, M. P. Little, V. Chumak, E. Bakhanova, D. Belyi, V. Kryuchkov, I. Golovanov, K. Mabuchi, I. Illienko, Y. Belayev, C. Bodelon, M. J. Machiela, A. Hutchinson, M. Yeager, A. B. de Gonzalez, S. J. Chanock, Field study of the possible effect of parental irradiation on the germline of children born to cleanup workers and evacuees of the Chornobyl nuclear accident. Am. J. Epidemiol. 189, 1451-1460 (2020). doi:10.1093/aje/kwaa095 Medline

28. A. S. Allen, S. F. Berkovic, P. Cossette, N. Delanty, D. Dlugos, E. E. Eichler, M. P. Epstein, T. Glauser, D. B. Goldstein, Y. Han, E. L. Heinzen, Y. Hitomi, K. B. Howell, M. R. Johnson, R. Kuzniecky, D. H. Lowenstein, Y. F. Lu, M. R. Madou, A. G. Marson, H. C. Mefford, S. Esmaeeli Nieh, T. J. O'Brien, R. Ottman, S. Petrovski, A. Poduri, E. K. Ruzzo, I. E. Scheffer, E. H. Sherr, C. J. Yuskaitis, B. Abou-Khalil, B. K. Alldredge, J. F. Bautista, S. F. Berkovic, A. Boro, G. D. Cascino, D. Consalvo, P. Crumrine, O. Devinsky, D. Dlugos, M. P. Epstein, M. Fiol, N. B. Fountain, J. French, D. Friedman, E. B. Geller, T. Glauser, S. Glynn, S. R. Haut, J. Hayward, S. L. Helmers, S. Joshi, A. Kanner, H. E. Kirsch, R. C. Knowlton, E. H. Kossoff, R. Kuperman, R. Kuzniecky, D. H. Lowenstein, S. M. McGuire, P. V. Motika, E. J. Novotny, R. Ottman, J. M. Paolicchi, J. M. Parent, K. Park, A. Poduri, I. E. Scheffer, R. A. Shellhaas, E. H. Sherr, J. J. Shih, R. Singh, J. Sirven, M. C. Smith, J. Sullivan, L. Lin Thio, A. Venkat, E. P. Vining, G. K. Von Allmen, J. L. Weisenberg, P. WiddessWalsh, M. R. Winawer; Epi4K Consortium; Epilepsy Phenome/Genome Project, De novo mutations in epileptic encephalopathies. Nature 501, 217-221 (2013). doi:10.1038/nature12439 Medline

29. Y. E. Dubrova, G. Grant, A. A. Chumak, V. A. Stezhka, A. N. Karakasian, Elevated minisatellite mutation rate in the post-chernobyl families from Ukraine. Am. J. Hum. Genet. 71, 801-809 (2002). doi:10.1086/342729 Medline

30. A. Kiuru, A. Auvinen, M. Luokkamäki, K. Makkonen, T. Veidebaum, M. Tekkel, M. Rahu, T. Hakulinen, K. Servomaa, T. Rytömaa, R. Mustonen, Hereditary minisatellite mutations among the offspring of Estonian Chernobyl cleanup workers. Radiat. Res. 159, 651-655 (2003). doi:10.1667/00337587(2003)159[0651:HMMAT0]2.0.C0:2 Medline

31. M. Kodaira, H. Ryo, N. Kamada, K. Furukawa, N. Takahashi, H. Nakajima, T. 
Nomura, N. Nakamura, No evidence of increased mutation rates at microsatellite loci in offspring of A-bomb survivors. Radiat. Res. 173, 205-213 (2010). doi:10.1667/RR1991.1 Medline

32. W. Zhou, M. J. Machiela, N. D. Freedman, N. Rothman, N. Malats, C. Dagnall, N. Caporaso, L. T. Teras, M. M. Gaudet, S. M. Gapstur, V. L. Stevens, K. B. Jacobs, J. Sampson, D. Albanes, S. Weinstein, J. Virtamo, S. Berndt, R. N. Hoover, A. Black, D. Silverman, J. Figueroa, M. Garcia-Closas, F. X. Real, J. Earl, G. Marenne, B. Rodriguez-Santiago, M. Karagas, A. Johnson, M. Schwenn, X. Wu, J. Gu, Y. Ye, A. Hutchinson, M. Tucker, L. A. Perez-Jurado, M. Dean, M. Yeager, S. J. Chanock, Mosaic loss of chromosome $Y$ is associated with common variation near TCL1A. Nat. Genet. 48, 563-568 (2016). doi:10.1038/ng.3545 Medline

33. R. M. Cawthon, Telomere length measurement by a novel monochrome multiplex quantitative PCR method. Nucleic Acids Res. 37, e21 (2009). doi:10.1093/nar/gkn1027 Medline

34. H. S. Weinberg, A. B. Korol, V. M. Kirzhner, A. Avivi, T. Fahima, E. Nevo, S. Shapiro, G. Rennert, O. Piatak, E. I. Stepanova, E. Skvarskaja, Very high mutation rate in offspring of Chernobyl accident liquidators. Proc. R. Soc. London Ser. B 268, 1001-1005 (2001). doi:10.1098/rspb.2001.1650 Medline

35. L. A. Livshits, S. G. Malyarchuk, S. A. Kravchenko, G. H. Matsuka, E. M. Lukyanova, Y. G. Antipkin, L. P. Arabskaya, E. Petit, F. Giraudeau, P. Gourmelon, G. Vergnaud, B. Le Guen, Children of chernobyl cleanup workers do not show elevated rates of mutations in minisatellite alleles. Radiat. Res. 155, 74-80 (2001). doi:10.1667/0033-7587(2001)155[0074:COCCWD]2.0.C0:2 Medline

36. J. D. Boice Jr., The likelihood of adverse pregnancy outcomes and genetic disease (transgenerational effects) from exposure to radioactive fallout from the 1945 Trinity atomic bomb test. Health Phys. 119, 494-503 (2020). doi:10.1097/HP.0000000000001170 Medline

37. A. B. Adewoye, S. J. Lindsay, Y. E. Dubrova, M. E. Hurles, The genome-wide effects of ionizing radiation on mutation induction in the mammalian germline. Nat. Commun. 6, 6684 (2015). doi:10.1038/ncomms7684 Medline

38. L. Morton, D. M. Karyadi, C. Stewart, T. I. Bogdanova, E. T. Dawson, M. K. Steinberg, J. Dai, S. W. Hartley, S. J. Schonfeld, J. N. Sampson, Y. Maruvka, V. Kapoor, D. A. Ramsden, J. Carvajal-Garcia, C. M. Perou, J. S. Parker, M. Krznaric, M. Yeager, J. F. Boland, A. Hutchinson, B. D. Hicks, C. L. Dagnall, J. M. GastierFoster, J. Bowen, O. Lee, M. J. Machiela, E. K. Cahoon, A. V. Brenner, K. Mabuchi, V. Drozdovitch, S. Masiuk, M. Chepurny, L. Yu. Zurnadzhy, M. Hatch, A. Berrington de Gonzalez, G. A. Thomas, M. D. Tronko, G. Getz, S. J. Chanock, Radiation-related genomic profile of papillary thyroid cancer after the Chernobyl accident. Science 10.1126/science.abg2538 (2021). doi:10.1126/science.abg2538

39. T. C. A. Smith, P. F. Arndt, A. Eyre-Walker, Large scale variation in the rate of germ-line de novo mutation, base composition, divergence and diversity in humans. PLOS Genet. 14, e1007254 (2018). doi:10.1371/journal.pgen.1007254 Medline

40. V. Kryuchkov, V. Chumak, E. Maceika, L. R. Anspaugh, E. Cardis, E. Bakhanova, I. Golovanov, V. Drozdovitch, N. Luckyanov, A. Kesminiene, P. Voillequé, A. Bouville, Radrue method for reconstruction of external photon doses for Chernobyl liquidators in epidemiological studies. Health Phys. 97, 275-298 (2009). doi:10.1097/HP.0b013e3181ac9306 Medline

41. J. T. Robinson, H. Thorvaldsdóttir, W. Winckler, M. Guttman, E. S. Lander, G. Getz, J. P. Mesirov, Integrative genomics viewer. Nat. Biotechnol. 29, 24-26 (2011). doi:10.1038/nbt.1754 Medline

42. J. T. Robinson, H. Thorvaldsdóttir, A. M. Wenger, A. Zehir, J. P. Mesirov, Variant Review with the Integrative Genomics Viewer. Cancer Res. 77, e31-e34 (2017). doi:10.1158/0008-5472.CAN-17-0337 Medline

43. Y. E. Maruvka, K. W. Mouw, R. Karlic, P. Parasuraman, A. Kamburov, P. Polak, N. J. Haradhvala, J. M. Hess, E. Rheinbay, Y. Brody, A. Koren, L. Z. Braunstein, A. D’Andrea, M. S. Lawrence, A. Bass, A. Bernards, F. Michor, G. Getz, Analysis of somatic microsatellite indels identifies driver events in human tumors. Nat. Biotechnol. 35, 951-959 (2017). doi:10.1038/nbt.3966 Medline

44. R. J. Callicott, J. E. Womack, Real-time PCR assay for measurement of mouse telomeres. Comp. Med. 56, 17-22 (2006). Medline

45. A. L. Price, N. J. Patterson, R. M. Plenge, M. E. Weinblatt, N. A. Shadick, D. Reich, Principal components analysis corrects for stratification in genome-wide association studies. Nat. Genet. 38, 904-909 (2006). doi:10.1038/ng1847 Medline
46. M. P. Purdue, M. Johansson, D. Zelenika, J. R. Toro, G. Scelo, L. E. Moore, E. Prokhortchouk, X. Wu, L. A. Kiemeney, V. Gaborieau, K. B. Jacobs, W.-H. Chow, D. Zaridze, V. Matveev, J. Lubinski, J. Trubicka, N. Szeszenia-Dabrowska, J. Lissowska, P. Rudnai, E. Fabianova, A. Bucur, V. Bencko, L. Foretova, V. Janout, P. Boffetta, J. S. Colt, F. G. Davis, K. L. Schwartz, R. E. Banks, P. J. Selby, P. Harnden, C. D. Berg, A. W. Hsing, R. L. Grubb 3rd, H. Boeing, P. Vineis, F. Clavel-Chapelon, D. Palli, R. Tumino, V. Krogh, S. Panico, E. J. Duell, J. R. Quirós, M.-J. Sanchez, C. Navarro, E. Ardanaz, M. Dorronsoro, K.-T. Khaw, N. E. Allen, H. B. Bueno-deMesquita, P. H. M. Peeters, D. Trichopoulos, J. Linseisen, B. Ljungberg, K. Overvad, A. Tiønneland, I. Romieu, E. Riboli, A. Mukeria, O. Shangina, V. L. Stevens, M. J. Thun, W. R. Diver, S. M. Gapstur, P. D. Pharoah, D. F. Easton, D. Albanes, S. J. Weinstein, J. Virtamo, L. Vatten, K. Hveem, I. Njølstad, G. S. Tell, C. Stoltenberg, R. Kumar, K. Koppova, O. Cussenot, S. Benhamou, E. Oosterwijk, S. H. Vermeulen, K. K. H. Aben, S. L. van der Marel, Y. Ye, C. G. Wood, X. Pu, A. M. Mazur, E. S. Boulygina, N. N. Chekanov, M. Foglio, D. Lechner, I. Gut, S. Heath, H. Blanche, A. Hutchinson, G. Thomas, Z. Wang, M. Yeager, J. F. Fraumeni Jr., K. G. Skryabin, J. D. McKay, N. Rothman, S. J. Chanock, M. Lathrop, P. Brennan, Genome-wide association study of renal cell carcinoma identifies two susceptibility loci on 2p21 and 11q13.3. Nat. Genet. 43, 60-65 (2011). doi:10.1038/ng.723 Medline

47. H. M. Cann, C. de Toma, L. Cazes, M. F. Legrand, V. Morel, L. Piouffre, J. Bodmer, W. F. Bodmer, B. Bonne-Tamir, A. Cambon-Thomsen, Z. Chen, J. Chu, C. Carcassi, L. Contu, R. Du, L. Excoffier, G. B. Ferrara, J. S. Friedlaender, H. Groot, D. Gurwitz, T. Jenkins, R. J. Herrera, X. Huang, J. Kidd, K. K. Kidd, A. Langaney, A. A. Lin, S. Q. Mehdi, P. Parham, A. Piazza, M. P. Pistillo, Y. Qian, Q. Shu, J. Xu, S. Zhu, J. L. Weber, H. T. Greely, M. W. Feldman, G. Thomas, J. Dausset, L. L. Cavalli-Sforza, A human genome diversity cell line panel. Science 296, 261-262 (2002). doi:10.1126/science.296.5566.261b Medline

\section{ACKNOWLEDGMENTS}

The authors gratefully acknowledge the participants in the study overseen by the National Research Centre for Radiation Medicine in Kiev (Kyiv in Ukrainian). This work utilized the computational resources of the NIH HPC Biowulf cluster (http://hpc.nih.gov). We thank Geoff Tobias (National Cancer Institute) for assistance with data posting, and Ming-Hsueh Lin for assistance with data visualization. Funding: This research was supported by the Intramural Research Program of the Division of Cancer Epidemiology and Genetics of the National Cancer Institute. C.W.N. was supported by a Gerstner Scholars Fellowship from the Gerstner Family Foundation at the American Museum of Natural History and a Postdoctoral Research Fellowship from Academia Sinica. This project has been funded in whole or in part with Federal funds from the National Cancer Institute, National Institutes of Health, under Contract No. 75N910D00024. The Radiation Effects Research Foundation (RERF), Hiroshima and Nagasaki, Japan is a public interest foundation funded by the Japanese Ministry of Health, Labor and Welfare (MHLW) and the US Department of Energy (DOE). The opinions expressed by the authors are their own and this material should not be interpreted as representing the official viewpoint of the National Cancer Institute of the U.S. Department of Health and Human Services, U.S. Department of Energy or Japanese Ministry of Health, Labor and Welfare. Author contributions: The following authors conceptualized the study: D.Ba., A.B.d.G., S.J.C., P.K., and M.Y. The following authors designed the study methodology: D.Ba., A.B.d.G., S.J.C., V.C., D.Be., V.D., E.B., E.C., N.F., G.G., N.G., M.H., I.G., I.I., K.M., M.M., M.L., Y.M., N.N., P. A., P.K., C.S., V.K., Y.B., and M.Y. The following authors analyzed the genomic data: B.B., C.P., S.J.C., C.B., C.W.N., C.D., M.D., L.C., M.M., M.L., M.W., L.M., P.K., S.S., M.Y., and W.Z. The following authors collected or generated the study data: D.Ba., A.B.d.G., V.C., C.D., D.Be., V.D., E.B., N.G., A.H., I.G., I.I., and Y.B. The following authors contributed resources (study materials, patients, computing resources, or other analysis tools): B.B., D.Ba., A.B.d.G., V.C., C.D., D.Be., V.D., E.B., N.G., P.A., A.H., C.P., I.G., I.I., and Y.B. The following authors wrote the original draft: S.J.C., C.W.N., M.D., M.M., P.K., and M.Y. The following authors visualized the data: B.B., C.P., C.W.N., M.M., P.A., P.K., L.C., M.Y., and W.Z. The following authors supervised or managed the research: A.B.d.G., S.J.C., G.G., and M.Y. The following authors acquired funding for the study: S.J.C. All authors edited the final manuscript. Competing interests: G.G. receives research funds from IBM and Pharmacyclics and is an inventor on patent applications related to MuTect, ABSOLUTE, MutSig, 
MSMuTect, MSMutSig, MSIdetect, POLYSOLVER and TensorQTL. G.G. is a

founder, consultant and holds privately held equity in Scorpion Therapeutics. All other authors declare no competing interests. Data and materials availability:

Molecular data are available from the Genomic Data Commons:

https:/gdc.cancer.gov/about-data/publications/TRIO-CRU-2021, accessed

through the database of Genotypes and Phenotypes (dbGaP, accession

phs001163.v1.p1; www.ncbi.nlm.nih.gov/projects/gap/cgi-

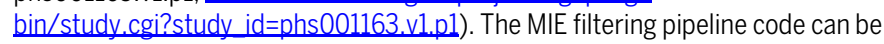
found at https://github.com/NCl-CGR/ChernobylDNMCalling.

\section{SUPPLEMENTARY MATERIALS}

science.sciencemag.org/cgi/content/full/science.abg2365/DC1

Materials and Methods

Figs. S1 to S7

Tables S1 to S10

References (40-47)

MDAR Reproducibility Checklist

22 December 2020; accepted 12 April 2021

Published online 22 April 2021

10.1126/science.abg2365 

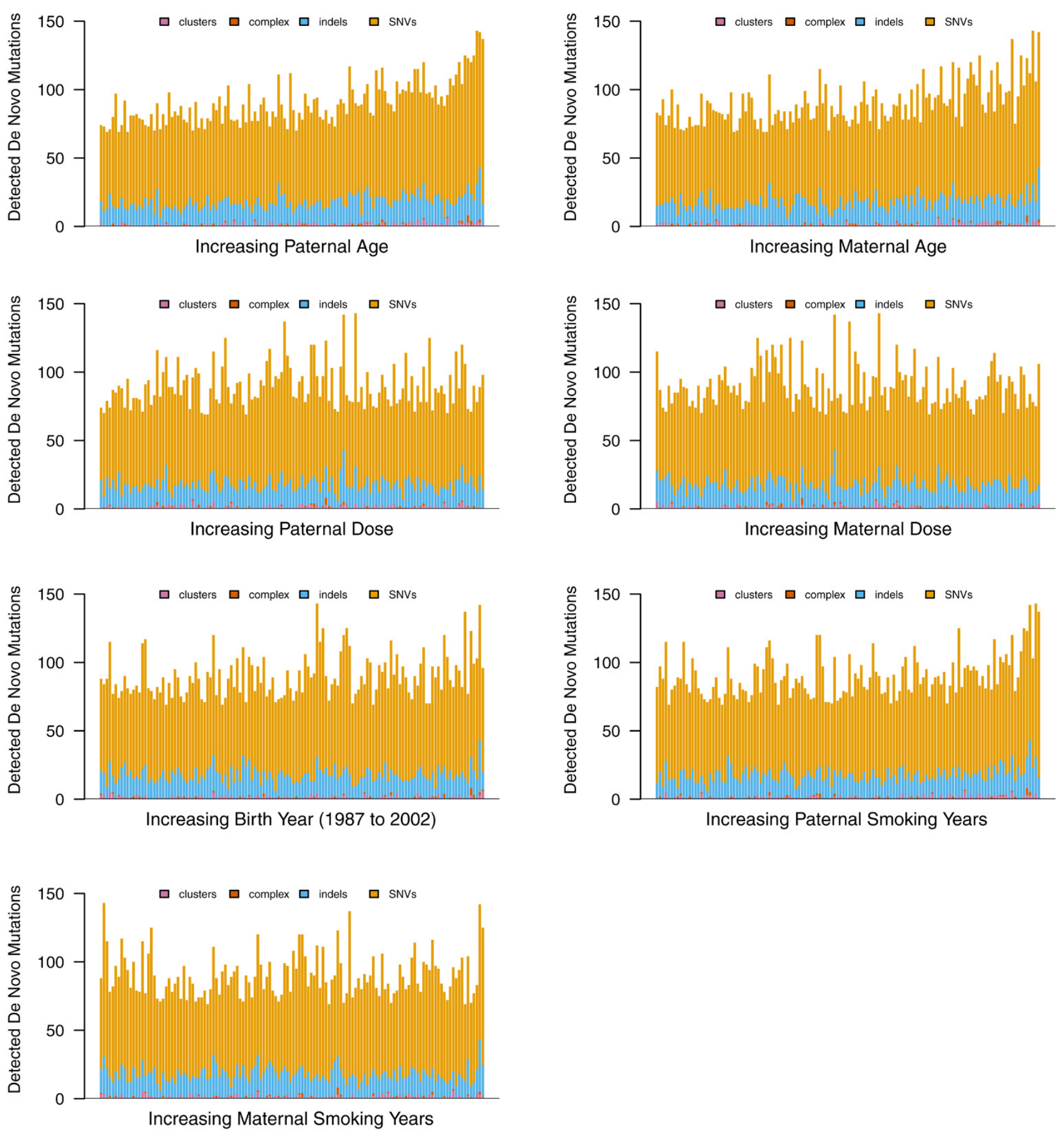

Fig. 1. Detected DNMs per genome based on distributions of parental age at conception. Analyses are presented by increasing paternal and maternal age at conception, paternal and maternal dose, birth year of child, and paternal and maternal smoking at conception. All plots are univariate and do not account for other potentially correlated variables (for example, maternal age does not account for high correlation with paternal age). 

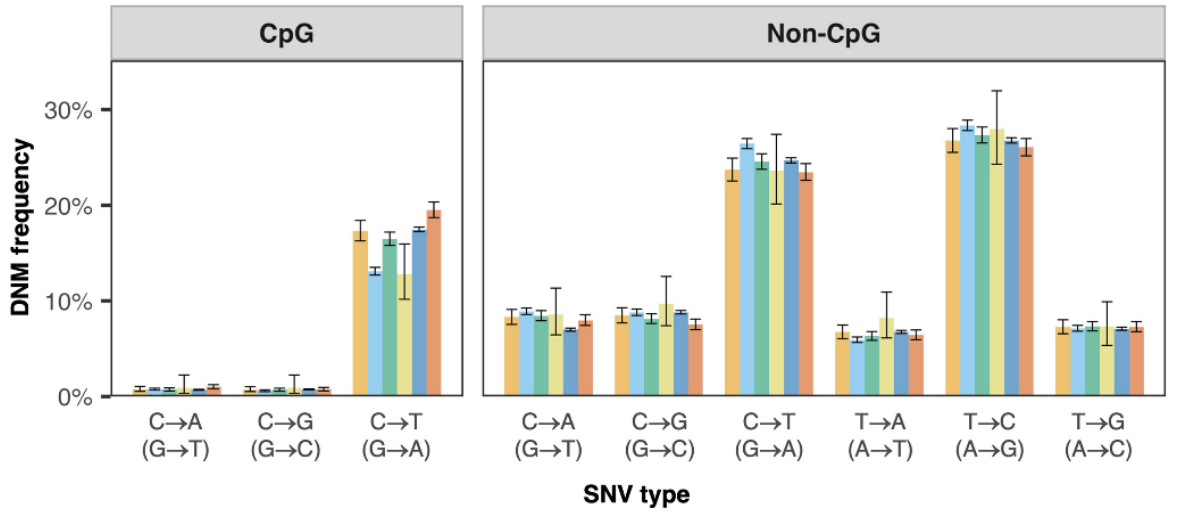

Study:

Kong $(n=78)$
Wong $(n=693)$

Francioli $(n=258)$

Michaelson $(n=20)$

Jónsson $(n=1,548)$

Chernobyl $(n=130)$

Fig. 2. Distribution of de novo SNVs by type of nucleotide change across six studies. $n=$ number of children sequenced (adapted from (39)). Liftover was used to convert coordinates to hg38 for all studies and the reference for $\mathrm{CpG}$ sites were defined with respect to that reference sequence. Only autosomes were included. Error bars show binomial 95\% confidence intervals. Studies included Kong (2); Wong (8); Francioli (4); Michaelson (3); Jónsson (6); and Chernobyl (present study). 
Table 1. Distribution of detected DNMs in the Chernobyl Trios. Results reported as events per diploid genome per generation and proportion phased to paternal and maternal haplotypes. Microsatellites are a smaller group within indels; the mean microsatellite count (5.62) is a part of the total mean indel count (16.18).

\begin{tabular}{lllll}
\hline & Mean & Median & Range & Standard Deviation \\
\hline Number of Clusters & 1.39 & 1 & $0-6$ & 1.34 \\
Number of Complex & 0.38 & 0 & $0-5$ & 0.77 \\
Number of Indels & 16.18 & 15 & $5-38$ & 5.10 \\
Number of Microsatellites & 5.62 & 5.5 & $0-13$ & 2.49 \\
Number of SNVs & 72.22 & 69.5 & $47-121$ & 13.36 \\
\hline Total Number of DNMs & 90.17 & 88 & $69-143$ & 15.94 \\
\hline Phased to Paternal Haplotype & 29.33 & 29 & $12-53$ & 7.08 \\
Phased to Maternal Haplotype & 8.61 & 8 & $2-20$ & 4.07 \\
Proportion Phased & $42.1 \%$ & $41.5 \%$ & $27.6-55.8 \%$ & $6.3 \%$ \\
\hline
\end{tabular}


Table 2. Associations of age at conception, cumulative ionizing radiation dose, and smoking history with DNM count. Multiple regression estimates for age and radiation dose are average changes in total DNMs per one unit increase in the respective variables. Smoking estimates are in comparison to never smokers. The model was additionally adjusted by sequencing batch.

\begin{tabular}{|c|c|c|c|}
\hline & Estimate & 95\% Confidence Interval & P-value \\
\hline \multicolumn{4}{|l|}{ Age at conception } \\
\hline Maternal age & 0.46 & $-0.02,0.93$ & 0.06 \\
\hline Paternal age & 1.94 & $1.51,2.36$ & $3.65 \times 10^{-15}$ \\
\hline \multicolumn{4}{|c|}{ Cumulative radiation dose (/mGy) } \\
\hline Maternal dose & -0.02 & $-0.04,0.007$ & 0.17 \\
\hline Paternal dose & -0.0007 & $-0.003,0.002$ & 0.56 \\
\hline \multicolumn{4}{|l|}{ Smoking history } \\
\hline Maternal former smoker & -4.13 & $-10.74,2.49$ & 0.22 \\
\hline Maternal current smoker & 5.31 & $-0.18,10.81$ & 0.06 \\
\hline Paternal former smoker & 0.91 & $-5.16,6.97$ & 0.77 \\
\hline Paternal current smoker & 2.91 & $-0.93,6.75$ & 0.14 \\
\hline
\end{tabular}


Table 3. Sensitivity analyses of the impact of maternal and paternal cumulative radiation dose modeling on association with DNMs. All models are adjusted for sequencing batch, maternal and paternal age, and maternal and paternal smoking status. Additional analyses by dose categories are in table S6.

\begin{tabular}{|c|c|c|c|}
\hline & Estimate & $95 \% \mathrm{Cl}$ & P-value \\
\hline \multicolumn{4}{|c|}{ Cumulative radiation dose (/mGy) } \\
\hline Maternal dose & -0.02 & $-0.04,0.007$ & 0.17 \\
\hline Paternal dose & -0.0007 & $-0.003,0.002$ & 0.56 \\
\hline \multicolumn{4}{|c|}{ Cumulative radiation dose truncated at 1,000 (/mGy) } \\
\hline Maternal dose & -0.02 & $-0.04,0.009$ & 0.21 \\
\hline Paternal dose & -0.003 & $-0.008,0.001$ & 0.17 \\
\hline \multicolumn{4}{|c|}{ Cumulative log radiation dose $(/ \ln (1+m G y))$} \\
\hline Maternal dose & -0.87 & $-2.12,0.39$ & 0.18 \\
\hline Paternal dose & -0.37 & $-1.07,0.33$ & 0.30 \\
\hline
\end{tabular}

